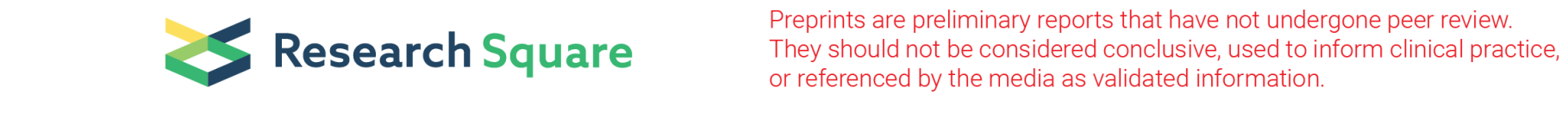

\title{
The Puzzle of Urban Density And Energy Consumption
}

Krzysztof Waśniewski ( $\nabla$ krzysztof.wasniewski@gmail.com )

The Andrzej Frycz-Modrzewski Krakow University https://orcid.org/0000-0003-0076-4804

\section{Research Article}

Keywords: urbanization, cities, urban density, energy consumption, demographic growth

Posted Date: March 22nd, 2021

DOI: https://doi.org/10.21203/rs.3.rs-343816/v1

License: (1) This work is licensed under a Creative Commons Attribution 4.0 International License. Read Full License 


\section{Abstract}

This article studies the broad socio-economic context of the otherwise known, yet intriguing a phenomenon of growing difference, in terms of density of population, between cities and the countryside. Empirical data collected in the here-presented research captures national idiosyncrasies covered by that global trend. A relatively novel empirical methodology is used to study that data, combining classical multiple regression with a heuristic transformation of data, as a Markov chain of states, with the use of an artificial neural network. That complex method is used for exploring and verifying the hypothesis that collective intelligence of human societies optimizes social interactions in the view of maximizing the absorption of energy from the environment. Both regression and artificial neural network substantiate the hypothesis, with probably more explanatory power to be found in the latter. Growing urban density seems to be instrumental, as type of social change, rather than a desired social outcome in itself.

JEL codes: R11; R12; R14; R15

\section{Introduction}

The idea of this article emerged as the author was cycling, on one of the first days of the COVID-19-related lockdown, through the streets of his hometown, i.e. Krakow, Poland. The quasi completely empty streets made the author ask a strange question: 'How many human footsteps per day does this city need to be really alive and functional as a social structure?. Working from home during lockdowns brought the realization that interaction via digital platforms can replace, to some extent, direct interactions. MS Teams can supplant cities to some extent. The 'some extent' part is interesting. To what specific extent do we need the intense human contacts, peculiar to city life?

Mankind is becoming more and more urbanized, i.e. a consistently growing percentage of people live in cities (World Bank 1). In 2007 2008 , the coefficient of urbanization topped $50 \%$ and keeps progressing since then. As there is more and more of us, humans, on the planet, we concentrate more and more in urban areas. That process defies preconceived ideas about land use. A commonly used narrative is that cities keep growing out into their once-non-urban surroundings, which is frequently confirmed by anecdotal, local evidence of particular cities effectively sprawling into the neighbouring rural land. Still, as data based on satellite imagery is brought up, and as total urban land area on Earth is measured as the total surface of peculiar agglomerations of man-made structures and night-time lights, that total area seems to be stationary, or, at least, to have been stationary for the last 30 years (World Bank 2). The geographical distribution of urban land over the entire land mass of Earth does change, yet the total seems to be pretty constant. In parallel, the total surface of agricultural land on Earth has been growing, although at a pace far from steady and predictable (World Bank 3).

There is a theory implied in the above-cited methodology of measuring urban land based on satellite imagery. Cities can be seen as demographic anomalies with a social purpose, just as Fernand Braudel used to state it (Braudel 1985) : 'Towns are like electric transformers. They increase tension, accelerate the rhythm of exchange and constantly recharge human life. [...]. Towns, cities, are turningpoints, watersheds of human history. [...]. The town [...] is a demographic anomaly. The basic theoretical thread of this article consists in viewing cities as complex technologies, for one, and in studying their transformations as a case of technological change. Logically, this is a case of technological change occurring by agglomeration and recombination. Cities can be studied as demographic anomalies with the specific purpose to accommodate a growing population with just as expanding a catalogue of new social roles, possible to structure into non-violent hierarchies. That path of thinking is present, for example, in the now classical work by Arnold Toynbee (Toynbee 1946), and in the even more classical take by Adam Smith (Smith 1763). Cities can literally work as factories of new social roles due to intense social interactions. The greater the density of population, the greater the likelihood of both new agglomerations of technologies being built, and new, adjacent social roles emerging. A good example of that special urban function is the interaction inside age groups. Historically, cities have allowed much more abundant interactions among young people (under the age of 25), that rural environments have. That, in turn, favours the emergence of social roles based on the typically adolescent, high appetite for risk and immediate rewards (see for example: Steinberg 2008). Recent developments in neuroscience, on the other hand, allow assuming that abundant social interactions in the urban environment have a deep impact on the neuroplastic change in our brains, and even on the phenotypical expression of human DNA (Ehninger et al. 2008; Bavelier et al. 2010; Day \& Sweatt 2011; Sweatt 2013)

At the bottom line of all those theoretical perspectives, cities are quantitatively different from the countryside by their abnormal density of population. Throughout this article, the acronymic symbol [DU/DG] is used to designate the density of urban population denominated in the units of (divided by) general density of population, and is computed on the grounds of data published by combining the above cited coefficient of urbanization (World Bank 1) with the headcount of population (World Bank 4), as well as with the surface of urban land (World Bank 2). The general density of population is taken straight from official statistics (World Bank 5). 
The [DU/DG] coefficient stays in the theoretical perspective of cities as demographic anomalies with a purpose, and it can be considered as a measure of social difference between cities and the countryside. It displays intriguing quantitative properties. Whilst growing steadily over time at the globally aggregate level, from 11,9 in 1961 to 19,3 in 2018, it displays significant disparity across space. Such countries as Mauritania or Somalia display a $[D U / D G]>600$, whilst United Kingdom or Switzerland are barely above $[D U / D G]=3$. In the 13 smallest national entities in the world, such as Tonga, Puerto Rico or Grenada, [DU/DG] falls below 1. In other words, in those ultra-small national structures, the method of assessing urban space by satellite-imagery-based agglomeration of night-time lights fails utterly. These communities display peculiar, categorially idiosyncratic a spatial pattern of settlement. The cross-sectional variability of [DU/DG] (i.e. its standard deviation across space divided by its cross-sectional mean value) reaches 8.62 , and yet some $70 \%$ of mankind lives in countries ranging across the $12,84 \leq[D U / D G] \leq 23,5$ interval.

Correlations which the [DU/DG] coefficient displays at the globally aggregate level (i.e. at the scale of the whole planet) are even more puzzling. When benchmarked against the global real output in constant units of value (World Bank 6), the time series of aggregate, global [DU/DG] displays a Pearson correlation of $r=0,9967$. On the other hand, the same type of Pearson correlation with the relative supply of money to the global economy (World Bank 7) yields $r=0,9761$. As the [DU/DG] coefficient is supposed to represent the relative social difference between cities and the countryside, a look at the latter is beneficial. The [DU/DG]Pearson-correlates with the global area of agricultural land (World Bank 8) at $r=0,9271$, and with the average, global yield of cereals, in kgs per hectare (World Bank 9), at $r=0,9858$. That strong correlations of the [DU/DG] coefficient with metrics pertinent to the global food base match its correlation with the energy base. When Pearson-correlated with the global average consumption of energy per capita (World Bank 10), [DU/DG] proves significantly covariant, at $r=0,9585$. All that kept in mind, it is probably not that much of a surprise to see the global aggregate [DU/DG] Pearson correlated with the global headcount of population (World Bank 11) at $r=0,9954$.

Before going further, it is important to re-assume the meaning of the [DU/DG] coefficient. This is essentially a metric of density in population, and density has abundant ramifications, so to say. The more people live per $1 \mathrm{~km}^{2}$, the more social interactions occur on the same square kilometre. Social interactions mean a lot. They mean learning by civilized rivalry. They mean transactions and markets as well. The greater the density of population, the greater the probability of new skills emerging, which possibly translates into new social roles, new types of business and new technologies. When two types of human settlements coexist, displaying very different densities of population, i.e. type $A$ being many times denser than type $B$, type $A$ is like a factory of patterns (new social roles and new markets), whilst type $B$ is the supplier of raw resources. The progressively growing global average [DU/DG]means that, at the scale of the human civilization, that polarity of social functions accentuates.

The [DU/DG] coefficient bears strong marks of a statistical stunt. It is based on truly risky the assumption, advanced implicitly by through the World Bank's data, that total surface of urban land on Earth has remained constant, at least over the last 3 decades. Moreover, denominating the density of urban population in units of general density of population was purely intuitive from the author's part, and, as a matter of fact, other meaningful denominators can easily come to one's mind. Still, with all that wobbly theoretical foundation, the [DU/DG] coefficient seems to inform about a significant, structural aspect of human societies. The Pearson correlations, which the global aggregate of that coefficient yields with the fundamental metrics of the global economy, are of an almost uncanny strength in social sciences, especially with respect to the strong cross-sectional disparity in the [DU/DG].

The relative social difference between cities and the countryside, measurable with the gauge of the [DU/DG] coefficient, seems to be a strongly idiosyncratic adaptative mechanism in human societies, and this mechanism seems to be correlated with quantitative growth in population, real output, production of food, and the consumption of energy. That could be a manifestation of tacit coordination, where a growing human population triggers an increasing pace of emergence in new social roles by stimulating urban density. As regards energy, the global correlation between the increasing [DU/DG] coefficient and the average consumption of energy per capita interestingly connects with a stream of research which postulates intelligent collective adaptation of human societies to the existing energy base, including intelligent spatial re-allocation of energy production and consumption (Leonard, Robertson 1997; Robson, Wood 2008; Russon 2010; Wasniewski 2017, 2020; Andreoni 2017; Heun et al. 2018; Velasco-Fernández et al 2018).

It is interesting to investigate how smart are human societies in shaping their idiosyncratic social difference between cities and the countryside. This specific path of research is being pursued, further in this article, through the verification and exploration of the following working hypothesis: 'The collective intelligence of human societies optimizes social interactions in the view of maximizing the absorption of energy from the environment'.

\section{The Method Of Empirical Research}


The relative social difference between cities and the countryside, as seen through the lens of relative density of population [DU/DG], seems to be informative about an adaptative mechanism in human societies. That mechanism seems to be coherent at the level of the whole planet (i.e. the whole human species), and strongly idiosyncratic at the local level, i.e. that of countries. Moreover, there seems to be a correlation, or at least recurrent coincidence, between the [DU/DG] coefficient and the consumption of energy. In order to verify and explore the hypothesis outlined in the introduction, an empirical dataset has been built, covering the variables named in the introduction, as well (i.e. the DU/DG coefficient, Population headcount, Urban population headcount, GDP in constant $\$ 2010$, Supply of broad money as \% of GDP, Energy consumption per capita in kgs of oil equivalent, Agricultural land in km2, and Cereal yield in kgs per hectare). All data has been sourced in databases publicly available with the World Bank and referenced in the introduction as 'World Bank [1 <> 11]'.

A sample of 21 countries has been selected, mostly with regard to snapshooting different levels and gradients in the [DU/DG]coefficient, and tentatively representative for different regions of the world. They are: Australia, Brazil, Canada, China, Colombia, France, Gabon, Germany, Ghana, India, Malaysia, Mexico, Mozambique, Namibia, New Zealand, Nigeria, Norway, Poland, Russian Federation, United Kingdom, and the United States. Due to limitations in the temporal span of that data, the window of observation ends in 2015, with various lengths, as specified in Table 1, in the Appendix, in the column labelled 'Year count back from 2015. The database covers a total of $N=896$ 'country <> year' observations. The mean [DU/DG] in the sample is $\mathbf{4 1 , 1 4}$, thus more than twice as big as the average global [DU/DG] presently. The intuition between this selection was to study a 'what if' hypothetical state of further increasing social difference between cities and the countryside, thus a hypothetical follow up on the trend observable up to now.

The entire database is available, in XLSX format, under the LINK HERE BELOW:

\section{https://discoversocialsciences.com/wp-content/uploads/2020/08/1st-dataset-non-missing.xlsx}

There are 4 worksheets in the file. The one labelled ' $7^{\text {st }}$ non missing' contains the raw data. The next sheet to the right is called ' $7^{s t} N M$ randomized and contains the same data in the form of a random combination. In the original database observations are grouped by countries, and inside each country-category, they are presented in temporal order, from earlier years to later years. One component of the quantitative method to be used consists in running the dataset through a neural network, which makes the outcome sensitive to the order of observations. The specific country-year order in the original database can induce the neural network into an unwanted bias. Therefore, data has been reshuffled into a random permutation. The next two sheets in that workbook are labelled, respectively, '1st NM STD' and '1st NM STD (2)', and they contain the randomized data in standardized form, i.e. denominated over the respective maximum of each variable. Once again, this is to be used in the neural network part of analysis.

The strong positive correlations between the [DU/DG] coefficient and the other variables studied, as outlined in the introduction, suggest some sort of test for autocorrelation. The specific method of testing used here is that of standardization on a cumulative basis. The basic logic of standardization consists in representing each observation as local deviation from the mean expected value, denominated in the units of standard deviation. The cumulative basis for standardization means that, for the $\boldsymbol{j}$ th instance of the variable ' $\boldsymbol{X}$, both the mean expected value and the standard deviation are computed for all the instances of $\boldsymbol{x}$ starting from the $1^{\text {st }}$ one up to the $\boldsymbol{j}$ th one in question. Mathematically, it takes the form of equation (1):

$$
\operatorname{std}\left(x_{j}\right)=\frac{\left[x_{j}-\operatorname{avg}\left(x_{1 \rightarrow j}\right)\right]}{\operatorname{std.dev}\left(x_{1 \rightarrow j}\right)}
$$

This is an order-sensitive standardization. When a variable is strongly autocorrelated, the curve of $\boldsymbol{s t d}\left(\boldsymbol{x}_{\boldsymbol{j}}\right)$ smoothens itself as $\boldsymbol{j}$ grows, with a sharp climb over the first few observations in the sequence, and then progressively passing into a horizontally asymptotic form. On the other hand, in the absence of significant autocorrelation, $\operatorname{std}\left(x_{j}\right)$ shapes into a shark-teeth-like pattern, without visible smoothing. Contingently to autocorrelation, each variable is being tested for its variability, i.e. for the ' $\operatorname{std} \cdot \operatorname{dev}(x) / \operatorname{mean}(x)^{\prime}$ proportion. The intuition behind this specific test is that variables endowed with relatively narrow a span of change are like skeletal bones of the social system studied, whilst those displaying considerably wide a band of variation can be compared to muscles, providing energy for movement.

The next phase of empirical analysis consists in studying covariance between the variables under scrutiny, in two steps: Pearson correlation, and linear OLS (Ordinary Least Squares) multiple regression. Pearson-correlating serves as direct comparison between the dataset studied, and the correlations between global aggregates, as presented in the introduction. Correlation is estimated at two levels: absolute values, on the one hand, and their natural logarithms, on the other hand. The latter can be considered as an approximation of local first derivatives in the values observed. 
Multiple regression assumes that each variable can be picked as a hypothetical outcome pursued by the societies studied, with the remaining variables treated as manifestation of instrumental action. The overall explanatory power of each multiple-regressed model (i.e. model focused on one specific variable as the explained phenomenon), as measured with the $R^{2}$ coefficient of determination, is tentatively informative about the role of each variable as collective outcome. At this point, it is important to bridge between the mathematical definition of errors, and the phenomenological one. Mathematically, error is an arithmetical difference between the expected value and the actual one. Phenomenologically, error means that arithmetical difference matters, i.e. we attach ethical value thereto.

Regression takes a bird's-eye-view of the data studied. A function is estimated, e.g. $y=a 1 *$ Population $+a 2 *$ supply of money $+\ldots+\boldsymbol{b}$, and is optimized so as to minimize standard error between the estimated $y$ s and the real ones. Minimizing standard error means that we apprehend all the empirical instances at once, as if the researcher was able to observe them all in the same time. With $\boldsymbol{m}$ variables in the game, regression informs about the strictly objective alignment of ' $m-1$ 'variables on the remaining one, the ' $y$ of multiple regression.

An alternative view is possible, where errors of estimation form a heuristic chain of learning. The variables studied - [DU/DG], population, urban population, GDP, velocity of money, energy consumed per capita, surface of agricultural land, and cereal yield per hectare - are observable manifestations of human activity, and each variable shows a different aspect thereof. A dataset structured into such variables is a complex description of human activity in many distinct instances, where each 'country <> year' observation is a separate phenomenal instance. In other words, socio-economic variables are informative about recurrent patterns in human behaviour as well as about its recurrent outcomes. Mathematically, the entire dataset can be considered as a Markov chain of states, with each 'country <> year' observation being a distinct state, chained to other states through a hypothetical $\sigma$-algebra. Each random permutation of $\mathrm{N}=896 \mathrm{states}$, accompanied by $N-1$ transformative $\sigma$-algebras, is one state space among the $896^{896}$ possible ones. There is a special case among such state spaces, namely that where all the $\mathrm{N}=896$ states are linked through a recurrent, structurally stable $\sigma$-algebra. Such a $\sigma$-algebra can be considered as representative for a process of collective learning, where an intelligent human social structure learns by experimenting with itself, i.e. by producing many local instances of itself.

The general logical structure of an artificial neural network can satisfy the conditions for such a $\sigma$-algebra, and it allows simulating chained actions in a network of Conscious Agents (Hoffman et al. 2015; Fields et al. 2018). In the last phase of the here-presented method, the empirical dataset of $\mathrm{N}=896$ 'country <> year' observations is processed with a simple neural network (i.e. a multi-layer perceptron), in order to simulate the process of collectively intelligent adaptation mediated by or possibly oriented on the optimization of the relative social difference between cities and the countryside, as measured with the [DU/DG] coefficient. The purpose of the simulation is twofold. Firstly, it is to deepen the insights offered by the OLS multiple regression and to deconstruct the set of 8 variables into a hierarchy of socially desired outcomes (i.e. collective contextual ethical values). Secondly, and accessorily, sensitivity to external disturbances can be studied.

The logical architecture of the neural network used here is defined according to 5 fundamental characteristics: i) distinction between the output variable and the input variables ii) self-observation of internal coherence iii) aggregation of input iv) neural activation and $v$ ) estimation of error. Traits (ii) $\div$ (v) are constant, whilst trait (i) is declined into 8 alternative versions, following a logic similar to multiple regression, described earlier in this section. With 8 variables in the dataset, 8 alternative structures of the neural network can be defined, each oriented on optimizing the vector of 7 inputs in the view of minimizing error in estimating the value of the $8^{\text {th }}$ variable, chosen as output. In each of those 8 alternative structures, input data is being standardized, and aggregated into $\mathrm{N}=896$ perceptual vectors ' $h$ ' as in equation (2). In the $j$-th perceptual vector $h_{j}$, the standardized value of the $i$-th input variable $\boldsymbol{x}_{i}$ is incremented with the error $e_{j-1}$, propagated from the preceding, $j-7$-th experimental round of learning, and the incremented value is then weighed with two parameters. The $E\left(x_{i, j}\right)$ parameter endogenous to the network. It is the Euclidean distance between the input variable $x_{i}$ and the remaining 6 input variables in the same $j$-th experimental round. Its presence in equation (2) represents the internal coherence of the social system studied, as - which has already been stated before - all the variables studied are assumed to show different quantitative aspects of essentially the same set of behavioural patterns in humans. The $R \sim U([0,1])$ parameter is exogenous and quasi-random in the interval between 0 and 1 . Its forces the network to experiment with different magnitudes of importance attached to input variables.

$$
h_{j}=\sum_{i=1}^{n} R \sim U([0,1]) * E\left(x_{i, j}\right) *\left(x_{i, j}+e_{j-1}\right)
$$

In a neural network, error is an endogenous dynamic parameter. In the here-presented methodology, error is estimated as in equation (3). The expected value of output variable $x_{0, j}$ is compared to the value yielded by the neural activation function, through the arithmetical operation of subtraction. Two alternative functions of neural activation compete for as accurate as possible an estimation of the expected output: the sigmoid $\left[1 /\left(1+e^{-h}\right)\right]$ and the hyperbolic tangent $\left[\left(e^{2 h}-1\right) /\left(e^{2 h}+1\right)\right]$. In each case, the observed residual difference between expected output $\boldsymbol{x}_{\boldsymbol{O}, j}$ and the experimental value produced through neural activation is being multiplied by (i.e. combined with) the local 
derivative of the corresponding activation function. The intuition behind this specific logical component is to capture both the stationary local value of a phenomenon, and its local gradient of change. The two alternative expressions in equation (3), i.e. neural activation multiplied by its local derivative, are essentially constants, modified by the presence of the perceptual vector $h$. In the case of the hyperbolic tangent, this constant is $-\left[\left(e^{2}-1\right) /\left(e^{2}+1\right)\right] *\left\{1-\left[\left(e^{2}-1\right) /\left(e^{2}+1\right)\right\}^{2}\right\}=-0,3198$, whilst the sigmoid activation yields a constant equal to $-\left[1 /\left(1+e^{-}\right.\right.$ $\left.\left.{ }^{h}\right)\right] /\left\{\left[1 /\left(1+e^{-h}\right)\right] *\left[1-1 /\left(1+e^{-h}\right)\right]\right\}=-0,196611933$. Thus, consistently with the above-cited theory of perception (Hoffman et al. 2015 op. cit.; Fields et al. 2018 op.cit.), it is assumed that Conscious Agents maintain a continuous state of general alertness, locally modified by perception.

$$
e_{j}=\min \left\{\begin{array}{c}
{\left[x_{o, j}-\frac{e^{2 h}-1}{e^{2 h}+1}\right] *\left[1-\left(\frac{e^{2 h}-1}{e^{2 h}+1}\right)^{2}\right]} \\
\left(x_{o, j}-\frac{1}{1+e^{-h}}\right) *\left[\frac{1}{1+e^{-h}} *\left(1-\frac{1}{1+e^{-h}}\right)\right]
\end{array}\right\}
$$

When the original dataset of $\mathrm{N}=896$ 'country <> year' observations is standardized over local maxima, and then processed with a looped sequence of equations (2) and (3), a modified version of that dataset is produced. For the sake of presentational convenience, the source empirical dataset will be further designated as $\boldsymbol{X}$, and each neural-network-generated transformation thereof, pegged on the specific variable $\boldsymbol{X}_{\boldsymbol{i}}$ as its output, is labelled $\boldsymbol{S}_{\boldsymbol{i}}$. All the sets $\boldsymbol{S}_{\boldsymbol{i}}$ can be considered as alternative states of reality represented by the set $\boldsymbol{X}$. Each specific $\sigma$-algebra made of the initial partition into input and output, combined with serially lopped equations (2) and (3), is a transition matrix, informative about a specific orientation of the intelligent collective depicted in the set $\boldsymbol{X}$. Each set $\boldsymbol{S}_{i}$ can be considered as a functional aspect of the source set $\boldsymbol{X}$, i.e. as a scenario 'what if humans in countries observed through the set $X$ oriented themselves on optimizing the specific variable $\boldsymbol{x}_{\boldsymbol{i}}$ as desired social outcome?.

It is further assumed that the more similar is the given set $\boldsymbol{S}_{i}$ to the source empirical set $\boldsymbol{X}$, the more accurate a representation it gives of the collective intelligence observable in set $\boldsymbol{X}$. Similarity is assessed by computing Euclidean distance between vectors of mean expected values in, respectively, the set $\boldsymbol{X}$ and the given set $\boldsymbol{S}_{\boldsymbol{i}}$ as in equation (4) below.

$E\left(X ; S_{i}\right)=\frac{\sum_{i=1}^{n} \sqrt{\left[\frac{\operatorname{avg}\left(S_{i ;} x_{i}\right)-\operatorname{avg}\left(X_{i} x_{i}\right)}{\operatorname{avg}\left(X_{i} x_{i}\right)}\right]^{2}}}{n}$

Ranking the 8 sets $S_{i}$ (corresponding to 8 variables in $\boldsymbol{X}$ ) as for their Euclidean similarity with $\boldsymbol{X}$ is informative about the relative functional role of variables which those sets are oriented on. It is assumed that the set $\boldsymbol{S}_{\boldsymbol{i}}$ which yields the lowest Euclidean distance to $\boldsymbol{X}$ is the most representative for the general orientation of collective action in the societies described. In the last phase of the here-presented method, that specific set $S_{i}$ is used to simulate the effects of random exogenous disturbance induced to the intelligent human collective. An exogenous variable labelled 'Factor of disturbance' is added to the neural network. Its exogeneity is assured by making it a series of random values generated by the software used to run the network. Each $j$ th standardized 'country $<>$ year' observation has a random disturbance assigned to it. A condition pertinent to that factor is added to equation (2): if Factor_of_disturbance $e_{j}>$ ej-1, then $E\left(x_{i, j}\right)=1$. In other words, when the random disturbance becomes significant, based on the immediately preceding experience of error, the network locally stops observing its own internal coherence, as measured with $E\left(x_{i, j}\right)$. Pegging $E\left(x_{i, j}\right)=1$ makes $E\left(x_{i, j}\right)$ non-significant in the perceptual vector $h$ equation (2). This simulates a situation when an external stressor loosens the ties of social coherence and contributes to creating new patterns of correlated behavioural coupling.

With the disturbance factor described above, another transformed set is produced, which is further labelled as $S_{i}$ (dist). Its Euclidean similarity $E\left[X ; S_{i}(d i s t)\right]$ to the source set $\boldsymbol{X}$ is assessed with equation (4). The greater that Euclidean distance, the greater the sensitivity of the intelligent human collective to random exogenous disturbances.

\section{Empirical Results}

The variables studied show no visible smoothing of curves traced on their values standardized with cumulative mean values and cumulative standard deviations. No significant autocorrelation is to notice. Table 2, in the Appendix, shows the coefficients of variability. The most movement comes from 'Population' and 'GDP', whilst the least change is to observe in 'Cereal yield per hectare', the supply of 'Broad money as \% of GDP' and 'Energy consumed per capita'. Velocity of money, agricultural productivity, and consumption of energy seem to make the skeleton, which, in turn, is being put in motion by demographic and economic growth. The [DU/DG]coefficient, with variability $\boldsymbol{v}=\mathbf{1 , 4 5 2 5 7 7 3 1}$, seems to be a factor of change rather than an axis of structural stability. 
Table 3, in the Appendix, displays the coefficients of Pearson correlation between the coefficient [DU/DG] and other variables. Natural logarithms seem to be more significantly correlated than base values. Whenever a significant correlation occurs, i.e. whenever the module based on the Pearson coefficient is greater than 0.3 , it is a negative correlation. This departs noticeably from the strong positive correlations observed at the aggregate planetary level and described in the Introduction. When haphazardly sampled, local idiosyncrasies in [DU/DG] seem to play out differently from the general global trends.

Tables 4 - 11, in the Appendix, give the results of multiple linear regression run, respectively, for explaining variance observed in each of the variables studied. All the 8 linear models seem quite robust, explanatory-power-wise. Their respective $\mathrm{R}^{2}$ coefficients of determination are pretty high, as for such a randomized dataset. Still, some are clearly higher than others. Models pegged on population, i.e. the absolute urban population and the absolute general population seem to be the strongest, displaying $R^{2}>0,9$. Interestingly, the [DU/DG]coefficient, thus the main suspect in this investigation, seems to be the least fit for the role of explained variable. The linear, multi-regressive model oriented on explaining the [DU/DG]yields the lowest explanatory power $\left(R^{2}=0,388\right)$.

Table 12, in the Appendix, summarizes the results of simulation run through the artificial neural network. Perceptron pegged on the consumption of energy per capita is $1-2$ orders of magnitude closer to the source set $X$, Euclidean-distance-wise, than the remaining 7 sets $S_{i}$. Sets formed by orienting the neural network on, respectively, the absolute headcount of urban population and the cereal yield per hectare, come in the second place as for similarity to $\boldsymbol{X}$. The clone $\boldsymbol{S}_{\boldsymbol{i}}$ oriented on optimizing the relative social difference between cities and the countryside, as measured with the coefficient [DU/DG], comes in the tail of the hierarchy in similarity. The neural network pegged on energy consumption per capita, as supposedly the most representative, has been tested as for its reaction to random exogenous disturbance in its internal coherence. The resulting vector of mean expected values falls quite close to the source set $\boldsymbol{X}$, at a Euclidean distance shorter than those observable in sets $\boldsymbol{S}_{i}$ pegged on, respectively, [DU/DG], Population, GDP, supply of broad money, and agricultural land.

\section{Final Discussion}

With growing a share of mankind living in cities, urban population of the world grows denser at a faster pace than the general one. To the extent that patterns of social interactions depend on the sheer number of humans per unit of available space, a civilisational change seems to be occurring. At the planetary scale, cities become more and more socially different from the countryside, and that trend is apparently connected to fundamental changes in the consumption of energy, the management of agricultural assets, and to sheer quantitative growth in population and in real output. Still, that complex phenomenon is strongly idiosyncratic in the cross-national perspective. The complex picture made of globally coherent trends contrasted with local specificities begs for broader development both in theoretical and empirical terms, as the COVID-19-related lockdowns have shown vividly the day-to-day, hardcore-business, ractical importance of intensity in social interactions.

This article introduces a complex quantitative method of studying empirically the phenomenon in question. The starting point of that method is the computation of the [DU/DG] coefficient, i.e. the ratio of density in urban population, divided by the general density of population. The line of logic developed in this article assumes that social densities are the base of social interactions, which, in turn, make the foundation of more complex social patterns. The [DU/DG] coefficient can be considered as a cold, objectivized metric concurrent with the 'framework of action' described in the classical Parson's theory (Parsons 1951-1991[1]). A sample of 21 countries has been selected for the purposes of the here-presented research, in the view of snapshooting very different levels and gradients in the [DU/DG] coefficient, as well as different geographic and economic contexts. The sample yields $N=896$ 'country <> year' observations, built, besides [DU/DG], around 7 other variables: population headcount, urban population headcount, real output, the velocity of money, surface of agricultural land, and cereal yield per hectare.

The whole dataset seems to be quite informative about local idiosyncrasies and partly contradicts correlations observable at the aggregate, planetary level. As Pearson correlations in that sampled set are compared with multiple linear regression, an interesting perspective emerges. Pearson correlations are rather weak, and autocorrelation seems being absent. Yet, multiple regression yields high explanatory power, whichever variable among the 8 studied is taken as the explained outcome. Complex functional connections seem being strong, whilst one-to-one correlations look weaker. An interesting theoretical perspective opens, where interaction between variables in the dataset is considered as manifestation of collectively intelligent, complex adaptation of human societies to constraints imposed by the available space, energy, and agricultural food base. That theoretical view translates as two alternative ways of estimating and testing functional connections between variables: multiple linear regression can be compared with the outcomes of treating the same data with a simple, artificial neural network. Multiple linear regression studies the dataset at hand from an external observer's point of view, where errors in 
estimating the output variable are all standardized at once. The artificial neural network produces a Markov chain of states, where each local error of estimation makes one step on a heuristic path of learning.

Whichever of the two perspectives should theoretically prevail, both concur as regards the function of relative urban density [DU/DG]: it is instrumental to other social outcomes, entailed by the 7 remaining variables of the dataset. From the perspective of multiple linear regression, the relative social difference between cities and the countryside is a means to optimize the headcount of population, both the general one, and the urban one in particular. Should the artificial neural network be the leading analytical view, the same [DU/DG] proportion is instrumental, most of all, to optimizing the consumption of energy per capita. Both methods of apprehending complex relations between the variables studied substantiate the working hypothesis of this article, namely that collective intelligence of human societies optimizes social interactions in the view of maximizing the absorption of energy from the environment. Still, the method based on heuristic treatment of data at hand with a neural network supplies more robust a confirmation for that claim, as compared to multiple regression. It can be tentatively concluded that artificial neural networks might be a privileged tool for virtual experimentation with empirical data whenever the concept of collective intelligent adaptation comes to the fore.

Those two views deserve deeper interpretation. Seeing urban density as a social contrivance serving to accommodate a growing population is a thought well rooted in social sciences. Arnold Toynbee, who studied civilisations as species endowed with specific lifecycles and survival traits, would claim, already in the 1940ies, that urban structures were invented by many civilisations in parallel and always served to build a rigid partition between inhabitable space for the lion's part of a rapidly growing population, and agricultural space serving to produce food (Toynbee 1946 op. cit.). When, on the other hand, we see cities and urbanization as instrumental to optimize the consumption of energy per capita, it is to keep in mind that the latter is based on the basket of technologies we use. Optimizing consumption of energy means adapting technologies to external stressors. In other words, the story told by the artificial neural network used in the here-presented research is the story of social difference between cities and the countryside, as measured with [DU/DG], being instrumental to energyoptimizing technological change. Urban structures are a demographic anomaly, and once this anomaly emerges, it brings written culture, which, in turn, allows the development of technology. This anomaly allows demographic growth (thus biological expansion of the human species) in the context of group rivalry for territory. The development of cities appears to be more productive an alternative to constant war. Once this alternative is chosen, cities allow the development of culture and technology. This is how they allow forming a rich palette of social roles. We, the human species, choose to be more and more crammed in cities, because such a demographic anomaly allows us to transmute growing population into a growing diversity of skills.

[1] Parsons T. 1951 - 1991, The Social System (new preface By Bryan S. Turner), First published in England 1951 by Routledge \& Kegan Paul Ltd, New edition first published 1991 by Routledge

\section{Declarations}

I, Krzysztof Wasniewski, hereby declare not having currently or having had in the past any competing interest as regards the underlying research of, and the writing of the manuscript titled "The Puzzle Of Urban Density And Energy Consumption."

Funding information: research presented in the manuscript has been funded from a grant of the Ministry Of Science and Higher Education of The Republic of Poland (PL: Ministerstwo Nauki i Szkolnictwa Wyższego Rzeczpospolitej Polskiej), grant \#: WZiKS/DS/7/2018-KON.

\section{References}

1. Andreoni, V. (2017). Energy Metabolism of 28 World Countries: A Multi-scale Integrated Analysis. Ecological Economics, 142, 56-69

2. Bavelier, D., Levi, D. M., Li, R. W., Dan, Y., \& Hensch, T. K. (2010). Removing brakes on adult brain plasticity: from molecular to behavioral interventions. Journal of Neuroscience, 30(45), 14964-14971. https://www.jneurosci.org/content/jneuro/30/45/14964.full.pdf

3. Braudel, F. (1985). Civilisation and Capitalism 15th and 18th Century-Vol. I: The Structures of Everyday Life, Translated by S. Reynolds, Collins, London, pp. 479 - 482

4. Day, J. J., \& Sweatt, J. D. (2011). Epigenetic mechanisms in cognition. Neuron, 70(5), 813-829.

https://doi.org/10.1016/j.neuron.2011.05.019

5. Ehninger, D., Li, W., Fox, K., Stryker, M. P., \& Silva, A. J. (2008). Reversing neurodevelopmental disorders in adults. Neuron, 60(6), 950960. https://doi.org/10.1016/j.neuron.2008.12.007

6. Fields, C., Hoffman, D. D., Prakash, C., \& Singh, M. (2018). Conscious agent networks: Formal analysis and application to cognition. Cognitive Systems Research, 47, 186-213. https://doi.org/10.1016/j.cogsys.2017.10.003 
7. Heun, M. K., Owen, A., \& Brockway, P. E. (2018). A physical supply-use table framework for energy analysis on the energy conversion chain. Applied Energy, 226, 1134-1162

8. Hoffman, D. D., Singh, M., \& Prakash, C. (2015). The interface theory of perception. Psychonomic bulletin \& review, $22(6), 1480-1506$.

9. Leonard, W.R., and Robertson, M.L. (1997). Comparative primate energetics and hominoid evolution. Am. J. Phys. Anthropol. 102, 265281.

10. Parsons T. 1951 - 1991, The Social System (new preface By Bryan S. Turner), First published in England 1951 by Routledge \& Kegan Paul Ltd, New edition first published 1991 by Routledge

11. Robson, S.L., and Wood, B. (2008). Hominin life history: reconstruction and evolution. J. Anat. 212, 394-425

12. Royal Institute of International Affairs, Somervell, D. C., \& Toynbee, A. (1946). A Study of History. By Arnold J. Toynbee... Abridgement of Volumes I-VI (VII-X.) by DC Somervell. Oxford University Press., Section 3: The Growths of Civilizations, Chapter X.

13. Russon, A. E. (2010). Life history: the energy-efficient orangutan. Current Biology, 20(22), pp. $981-983$.

14. Smith, A. (1763-1896). Lectures on justice, police, revenue and arms. Delivered in the University of Glasgow in 1763 , published by Clarendon Press in 1896, pp. 9 - 20

15. Steinberg, L. (2008). A social neuroscience perspective on adolescent risk-taking. Developmental review, 28(1), 78-106. https://dx.doi.org/10.1016\%2Fj.dr.2007.08.002

16. Sweatt, J. D. (2013). The emerging field of neuroepigenetics. Neuron, 80(3), 624-632. https://doi.org/10.1016/j.neuron.2013.10.023

17. Velasco-Fernández, R., Giampietro, M., \& Bukkens, S. G. (2018). Analyzing the energy performance of manufacturing across levels using the end-use matrix. Energy, 161, 559-572

18. Waśniewski, K. (2017). Technological change as intelligent, energy-maximizing adaptation. Energy-Maximizing Adaptation (August 30, 2017).

19. Wasniewski, K. (2020). Energy efficiency as manifestation of collective intelligence in human societies. Energy, 191, 116500.

20. World Bank 1: https://data.worldbank.org/indicator/SP.URB.TOTL.IN.ZS

21. World Bank 10: https://data.worldbank.org/indicator/EG.USE.PCAP.KG.OE

22. World Bank 11: https://data.worldbank.org/indicator/SP.POP.TOTL

23. World Bank 2: https://data.worldbank.org/indicator/AG.LND.TOTL.UR.K2

24. World Bank 3: https://data.worldbank.org/indicator/AG.LND.AGRI.K2

25. World Bank 4: https://data.worldbank.org/indicator/SP.POP.TOTL

26. World Bank 5: https://data.worldbank.org/indicator/EN.POP.DNST

27. World Bank 6: https://data.worldbank.org/indicator/NY.GDP.MKTP.KD

28. World Bank 7: https://data.worldbank.org/indicator/FM.LBL.BMNY.GD.ZS

29. World Bank 8: https://data.worldbank.org/indicator/AG.LND.AGRI.K2

30. World Bank 9: https://data.worldbank.org/indicator/AG.YLD.CREL.KG

\section{Appendix}

Table 1 


\begin{tabular}{|lllll|}
\hline Country & Year count back from 2015 & mean(DU/DG] $)$ & $\min (\mathrm{DU} / \mathrm{DG}]$ ) & $\max (\mathrm{DU} / \mathrm{DG}]$ ) \\
\hline Australia & 55 & 177,038 & 171,311 & 179,172 \\
\hline Brazil & 44 & 45,937 & 35,229 & 52,937 \\
\hline Canada & 55 & 55,383 & 50,077 & 58,408 \\
\hline China & 38 & 8,192 & 4,321 & 13,381 \\
\hline Colombia & 42 & 21,482 & 17,623 & 24,386 \\
\hline France & 54 & 4,664 & 3,965 & 5,041 \\
\hline Gabon & 44 & 209,878 & 104,986 & 270 \\
\hline Germany & 44 & 4,157 & 4,045 & 4,318 \\
\hline Ghana & 44 & 14,323 & 10,639 & 19,481 \\
\hline India & 44 & 3,485 & 2,669 & 4,324 \\
\hline Malaysia & 44 & 11,357 & 7,234 & 15,531 \\
\hline Mexico & 45 & 13,559 & 11,346 & 15,049 \\
\hline Mozambique & 24 & 85,036 & 73,171 & 97,26 \\
\hline Namibia & 24 & 118,087 & 93,142 & 152,883 \\
\hline New Zealand & 46 & 27,48 & 26,313 & 28,03 \\
\hline Nigeria & 44 & 16,418 & 9,613 & 24,883 \\
\hline Norway & 55 & 12,771 & 9,184 & 14,598 \\
\hline Poland & 26 & 6,152 & 6,051 & 6,205 \\
\hline Russian Federation & 14 & 64,269 & 64,061 & 64,577 \\
\hline United Kingdom & 55 & 3,247 & 3,175 & 3,405 \\
\hline United States & 55 & 8,685 & 8,037 & 9,311 \\
\hline
\end{tabular}

\section{Table 2}

\begin{tabular}{|ll|}
\hline Variable & $\begin{array}{c}\text { Coefficient of } \\
\text { variability }\end{array}$ \\
\hline VARIABILITY(DU/DG] ) & 1,45257731 \\
\hline VARIABILITY(Population) & 2,002539407 \\
\hline VARIABILITY(GDP (constant 2010 US\$)) & 1,856363162 \\
\hline VARIABILITY(Broad money (\% of GDP)) & 0,627015134 \\
\hline VARIABILITY(urban population absolute) & 1,579911888 \\
\hline VARIABILITY(Energy use (kg of oil equivalent per capita)) & 0,795818029 \\
\hline VARIABILITY(agricultural land km2) & 1,316125923 \\
\hline VARIABILITY(Cereal yield (kg per hectare)) & 0,595598827 \\
\hline VARIABILITY(Cereal yield (kg per hectare) $\times$ agricultural land km2 / Population) & 1,660988194 \\
\hline $\begin{array}{l}\text { VARIABILITY(Cereal yield (kg per hectare) } \times \text { agricultural land km2 / Population / Energy use (kg of oil } \\
\text { equivalent per capita)) }\end{array}$ & 1,183172781 \\
\hline
\end{tabular}

Table 3 


\begin{tabular}{|lcc|}
\hline \multicolumn{3}{|c|}{ Variable to correlate... } \\
\hline & [DU/DG] & Ln[DU/DG] \\
\hline Pearson-correlated with... & & \\
\hline Population & $-0,242$ & $-0,335$ \\
\hline In(Population) & $-0,520$ & $-0,554$ \\
\hline GDP (constant 2010 US\$) & $-0,207$ & $-0,249$ \\
\hline In(GDP (constant 2010 US\$)) & $-0,394$ & $-0,457$ \\
\hline Broad money (\% of GDP) & $-0,224$ & $-0,279$ \\
\hline In(Broad money (\% of GDP)) & $-0,238$ & $-0,299$ \\
\hline urban population absolute & $-0,263$ & $-0,371$ \\
\hline In(urban population absolute) & $-0,496$ & $-0,531$ \\
\hline Energy use (kg of oil equivalent per capita) & 0,046 & 0,050 \\
\hline In(Energy use (kg of oil equivalent per capita)) & 0,083 & 0,039 \\
\hline agricultural land km2 & 0,195 & 0,158 \\
\hline In(agricultural land km2) & 0,083 & 0,111 \\
\hline Cereal yield (kg per hectare) & $-0,443$ & $-0,532$ \\
\hline In(Cereal yield (kg per hectare)) & $-0,469$ & $-0,547$ \\
\hline
\end{tabular}

Table 4 - Explained variable : Std (DU/DG) $R^{2}=0,388$

\begin{tabular}{|lllll|}
\hline Explanatory variable & coefficient & std. error & t-statistic & p-value \\
\hline std(Population) & $-0,307$ & 0,06 & $-5,1$ & 0,0000 \\
\hline $\operatorname{std(GDP~(constant~2010~US\$ ))~}$ & $-0,193$ & 0,035 & $-5,45$ & 0,0000 \\
\hline $\operatorname{std(Broad~money~(\% ~of~GDP))~}$ & 0,097 & 0,031 & 3,099 & 0,0020 \\
\hline std(urban population absolute) & $-0,131$ & 0,084 & $-1,561$ & 0,1188 \\
\hline std(Energy use (kg of oil equivalent per capita)) & 0,07 & 0,025 & 2,77 & 0,0057 \\
\hline $\operatorname{std(agricultural~land~km2)~}$ & 0,491 & 0,035 & 13,836 & 0,0000 \\
\hline $\operatorname{std(Cereal~yield~(kg~per~hectare))~}$ & $-0,367$ & 0,028 & $-13,14$ & 0,0000 \\
\hline constant & 0, & 0,026 & 0, & 1,0000 \\
\hline
\end{tabular}

Table 5 - Explained variable : Std (Population) $R^{2}=0,906$ 


\begin{tabular}{|c|c|c|c|c|}
\hline Explanatory variable & coefficient & std. error & t-statistic & p-value \\
\hline $\operatorname{std}(D U / D G])$ & $-0,047$ & 0,014 & $-3,493$ & 0,001 \\
\hline std(GDP (constant 2010 US\$)) & $-0,315$ & 0,022 & $-14,397$ & 0,000 \\
\hline std(Broad money (\% of GDP)) & $-0,046$ & 0,014 & $-3,348$ & 0,001 \\
\hline std(urban population absolute) & 1,039 & 0,04 & 25,975 & 0,000 \\
\hline $\operatorname{std}($ Energy use ( $\mathrm{kg}$ of oil equivalent per capita)) & $-0,011$ & 0,012 & $-0,978$ & 0,328 \\
\hline std(agricultural land km2) & 0,054 & 0,028 & 1,912 & 0,056 \\
\hline std(Cereal yield (kg per hectare)) & 0,015 & 0,016 & 0,976 & 0,329 \\
\hline constant & 0 & 0,01 & 0 & 1,000 \\
\hline
\end{tabular}

Table 6 - Explained variable : Std [GDP (constant 2010 US\$)] $\mathbf{R}^{2}=0,721$

\begin{tabular}{|lllll|}
\hline Explanatory variable & coefficient & std. error & t-statistic & p-value \\
\hline $\operatorname{std}(\mathrm{DU} / \mathrm{DG}]$ ) & $-0,088$ & 0,017 & $-5,116$ & 0,000 \\
\hline $\operatorname{std}($ Population) & $-0,933$ & 0,076 & $-12,278$ & 0,000 \\
\hline $\operatorname{std(Broad~money~(\% ~of~GDP))~}$ & $-0,197$ & 0,033 & $-5,935$ & 0,000 \\
\hline $\operatorname{std}($ urban population absolute) & 1,242 & 0,104 & 11,934 & 0,000 \\
\hline $\operatorname{std}($ Energy use (kg of oil equivalent per capita)) & 0,291 & 0,024 & 11,976 & 0,000 \\
\hline $\operatorname{std(agricultural~land~km2)~}$ & 0,188 & 0,026 & 7,348 & 0,000 \\
\hline $\operatorname{std}($ Cereal yield (kg per hectare)) & 0,253 & 0,033 & 7,672 & 0,000 \\
\hline $\operatorname{constant}$ & 0, & 0,018 & 0, & 1,000 \\
\hline
\end{tabular}

Table 7 - Explained variable : Std [Broad money (\% of GDP)] $\mathrm{R}^{2}=0,546$

\begin{tabular}{|lllll|}
\hline Explanatory variable & coefficient & std. error & t-statistic & p-value \\
\hline std(DU/DG] ) & 0,072 & 0,027 & 2,706 & 0,007 \\
\hline $\operatorname{std(Population)~}$ & $-0,223$ & 0,05 & $-4,428$ & 0,000 \\
\hline std(GDP (constant 2010 US\$)) & $-0,32$ & 0,028 & $-11,501$ & 0,000 \\
\hline std(urban population absolute) & 0,647 & 0,067 & 9,61 & 0,000 \\
\hline std(Energy use (kg of oil equivalent per capita)) & 0,315 & 0,036 & 8,86 & 0,000 \\
\hline std(agricultural land km2) & $-0,036$ & 0,029 & $-1,211$ & 0,226 \\
\hline std(Cereal yield (kg per hectare)) & 0,573 & 0,029 & 19,665 & 0,000 \\
\hline constant & 0, & 0,023 & 0, & 1,000 \\
\hline
\end{tabular}

Table 8 - Explained variable : Std [urban population absolute] $R^{2}=0,932$ 


\begin{tabular}{|lllll|}
\hline Explanatory variable & coefficient & std. error & t-statistic & p-value \\
\hline $\operatorname{std}(\mathrm{DU} / \mathrm{DG}]$ ) & $-0,015$ & 0,008 & $-1,767$ & 0,078 \\
\hline $\operatorname{std}($ Population) & 0,749 & 0,021 & 36,178 & 0,000 \\
\hline $\operatorname{std}($ GDP (constant 2010 US\$)) & 0,303 & 0,022 & 13,809 & 0,000 \\
\hline $\operatorname{std(Broad~money~(\% ~of~GDP))~}$ & 0,097 & 0,022 & 4,436 & 0,000 \\
\hline std(Energy use (kg of oil equivalent per capita)) & $-0,088$ & 0,013 & $-6,839$ & 0,000 \\
\hline $\operatorname{std}($ agricultural land km2) & 0,086 & 0,015 & 5,872 & 0,000 \\
\hline $\operatorname{std}($ Cereal yield (kg per hectare)) & $-0,01$ & 0,013 & $-0,727$ & 0,467 \\
\hline constant & 0, & 0,009 & 0, & 1,000 \\
\hline
\end{tabular}

Table 9 - Explained variable : Std [Energy use ( $\mathrm{kg}$ of oil equivalent per capita)] $\mathrm{R}^{2}=0,548$

\begin{tabular}{|lllll|}
\hline Explanatory variable & coefficient & std. error & t-statistic & p-value \\
\hline $\operatorname{std(DU/DG]~)~}$ & 0,052 & 0,018 & 2,948 & 0,003 \\
\hline $\operatorname{std(Population)~}$ & $-0,054$ & 0,054 & $-0,998$ & 0,319 \\
\hline $\operatorname{std(GDP}$ (constant 2010 US\$)) & 0,471 & 0,041 & 11,464 & 0,000 \\
\hline $\operatorname{std(Broad~money~(\% ~of~GDP))~}$ & 0,313 & 0,041 & 7,589 & 0,000 \\
\hline $\operatorname{std(urban~population~absolute)~}$ & $-0,585$ & 0,06 & $-9,776$ & 0,000 \\
\hline $\operatorname{std(agricultural~land~km2)~}$ & 0,336 & 0,026 & 13,105 & 0,000 \\
\hline $\operatorname{std(Cereal~yield~(kg~per~hectare))~}$ & 0,159 & 0,037 & 4,28 & 0,000 \\
\hline constant & 0, & 0,023 & 0, & 1,000 \\
\hline
\end{tabular}

Table 10 - Explained variable : Std [agricultural land km2] $R^{2}=0,635$

\begin{tabular}{|lllll|}
\hline Explanatory variable & coefficient & std. error & t-statistic & p-value \\
\hline $\operatorname{std(DU/DG]~)~}$ & 0,293 & 0,044 & 6,667 & 0,000 \\
\hline $\operatorname{std(Population)~}$ & 0,21 & 0,1 & 2,109 & 0,035 \\
\hline $\operatorname{std(GDP~(constant~2010~US\$ ))~}$ & 0,246 & 0,03 & 8,212 & 0,000 \\
\hline $\operatorname{std(Broad~money~(\% ~of~GDP))~}$ & $-0,029$ & 0,023 & $-1,241$ & 0,215 \\
\hline std(urban population absolute) & 0,464 & 0,102 & 4,527 & 0,000 \\
\hline std(Energy use (kg of oil equivalent per capita)) & 0,272 & 0,028 & 9,542 & 0,000 \\
\hline $\operatorname{std(Cereal~yield~(kg~per~hectare))~}$ & $-0,241$ & 0,028 & $-8,552$ & 0,000 \\
\hline constant & 0, & 0,02 & 0, & 1,000 \\
\hline
\end{tabular}

Table 11 - Explained variable : Std [Cereal yield ( $k g$ per hectare)] $\mathrm{R}^{2}=0,626$ 


\begin{tabular}{|lllll|}
\hline Explanatory variable & coefficient & std. error & t-statistic & p-value \\
\hline $\operatorname{std(DU/DG]~)~}$ & $-0,224$ & 0,021 & $-10,653$ & 0,000 \\
\hline $\operatorname{std(Population)~}$ & 0,061 & 0,06 & 1,016 & 0,310 \\
\hline std(GDP (constant 2010 US\$)) & 0,338 & 0,026 & 12,837 & 0,000 \\
std(Broad money (\% of GDP)) & 0,472 & 0,033 & 14,186 & 0,000 \\
\hline std(urban population absolute) & $-0,053$ & 0,069 & $-0,764$ & 0,445 \\
\hline std(Energy use (kg of oil equivalent per capita)) & 0,132 & 0,034 & 3,845 & 0,000 \\
\hline std(agricultural land km2) & $-0,247$ & 0,027 & $-9,204$ & 0,000 \\
\hline constant & 0, & 0,021 & 0, & 1,000 \\
\hline
\end{tabular}

Table 12 - Vectors of mean values yielded by neural networks pegged on particular variables in the dataset 


\begin{tabular}{|c|c|c|c|c|c|c|c|c|c|}
\hline \multicolumn{10}{|c|}{ Mean values... } \\
\hline $\begin{array}{l}\text { Perceptron } \\
\text { pegged } \\
\text { on... }\end{array}$ & [DU/DG] & $\begin{array}{l}\text { Population } \\
\text { [millions] }\end{array}$ & $\begin{array}{l}\text { GDP } \\
\text { (millions } \\
\text { od } \\
\text { constant } \\
2010 \\
\text { US\$) }\end{array}$ & $\begin{array}{l}\text { Broad } \\
\text { money } \\
\text { (\% of } \\
\text { GDP) }\end{array}$ & $\begin{array}{l}\text { urban } \\
\text { population } \\
\text { absolute } \\
\text { [millions] }\end{array}$ & $\begin{array}{l}\text { Energy } \\
\text { use (kg of } \\
\text { oil } \\
\text { equivalent } \\
\text { per } \\
\text { capita) }\end{array}$ & $\begin{array}{l}\text { agricultural } \\
\text { land km2 }\end{array}$ & $\begin{array}{l}\text { Cereal } \\
\text { yield } \\
\text { (kg per } \\
\text { hectare) }\end{array}$ & $\begin{array}{l}\text { Standardized } \\
\text { Euclidean } \\
\text { distance from } \\
\text { source set X }\end{array}$ \\
\hline [DU/DG] & 30,62 & 96,493 & 669,224 & 50,04 & 38,520 & $\begin{array}{c}2 \\
589,38\end{array}$ & $\begin{array}{c}1023 \\
349,56\end{array}$ & $\stackrel{2}{837,63}$ & 0,25507938 \\
\hline Population & 27,31 & 79,734 & 463,949 & 47,69 & 29,427 & $\begin{array}{c}2 \\
485,51\end{array}$ & $\begin{array}{c}959 \\
019,29\end{array}$ & $\begin{array}{c}2 \\
738,06\end{array}$ & 0,33553606 \\
\hline $\begin{array}{l}\text { GDP } \\
\text { (constant } \\
2010 \text { US\$) }\end{array}$ & 27,17 & 79,054 & 455,631 & 47,59 & 29,058 & $\begin{array}{c}2 \\
481,31\end{array}$ & $\begin{array}{r}956 \\
412,45\end{array}$ & $\begin{array}{c}2 \\
734,02\end{array}$ & 0,33879639 \\
\hline $\begin{array}{l}\text { Broad } \\
\text { money (\% } \\
\text { of GDP) }\end{array}$ & 35,20 & 119,6 & 952,254 & 53,29 & 51,057 & $\begin{array}{c}2 \\
732,60\end{array}$ & $\begin{array}{r}1112 \\
047,33\end{array}$ & $\begin{array}{c}2 \\
974,92\end{array}$ & 0,14414672 \\
\hline $\begin{array}{l}\text { urban } \\
\text { population } \\
\text { absolute }\end{array}$ & 37,01 & 128,755 & 1064,396 & 54,57 & 56,025 & $\begin{array}{c}2 \\
789,34\end{array}$ & $\begin{array}{c}1147 \\
191,16\end{array}$ & $\begin{array}{c}3 \\
029,31\end{array}$ & 0,10019298 \\
\hline $\begin{array}{l}\text { Energy use } \\
\text { (kg of oil } \\
\text { equivalent } \\
\text { per capita) }\end{array}$ & 41,06 & 149,229 & 1315,171 & 57,45 & 67,134 & $\begin{array}{c}2 \\
916,24\end{array}$ & $\begin{array}{c}1225 \\
780,76\end{array}$ & $\begin{array}{c}3 \\
150,95\end{array}$ & 0,00190241 \\
\hline $\begin{array}{l}\text { agricultural } \\
\text { land km2 }\end{array}$ & 34,87 & 117,942 & 931,946 & 53,05 & 50,158 & $\begin{array}{c}2 \\
722,32\end{array}$ & $\begin{array}{l}1105 \\
683,25\end{array}$ & $\begin{array}{l}2 \\
965,07\end{array}$ & 0,15210615 \\
\hline $\begin{array}{l}\text { Cereal } \\
\text { yield (kg } \\
\text { per } \\
\text { hectare) }\end{array}$ & 36,65 & 126,957 & 1042,378 & 54,32 & 55,050 & $\begin{array}{c}2 \\
778,20\end{array}$ & $\begin{array}{c}1140 \\
290,95\end{array}$ & $\begin{array}{c}3 \\
018,63\end{array}$ & 0,10882294 \\
\hline $\begin{array}{l}\text { Source set } \\
\text { X }\end{array}$ & 41,14 & 149,625 & 1320,025 & 57,50 & 67,349 & 2918,69 & $\begin{array}{r}1227 \\
301,86\end{array}$ & $\stackrel{3}{153,31}$ & \\
\hline $\begin{array}{l}\text { Energy use } \\
\text { (kg of oil } \\
\text { equivalent } \\
\text { per capita) } \\
\text { - randomly } \\
\text { disturbed } \\
\text { in internal } \\
\text { coherence }\end{array}$ & 36,71 & 127,253 & 1045,996 & 54,36 & 55,210 & $\begin{array}{c}2 \\
780,03\end{array}$ & $\begin{array}{r}1141 \\
424,76\end{array}$ & $\begin{array}{c}3 \\
020,39\end{array}$ & 0,1074049 \\
\hline
\end{tabular}

